\title{
Dinâmica temporal de focos de calor e seus condutores de pressão no território do Sudeste Paraense
}

\author{
Thiago FERNANDES ${ }^{1}$, Sandra de Souza HACON ${ }^{2}$, Jonathan Willian Zangeski NOVAIS ${ }^{3}$
}

\author{
${ }^{1}$ Universidade Federal Rural da Amazônia (UFRA), Parauapebas, PA, Brasil \\ ${ }^{2}$ Escola Nacional de Saúde Pública (FIOCRUZ), Rio de Janeiro, RJ, Brasil. \\ ${ }^{3}$ Universidade de Cuiabá (UNIC), Cuiabá, MT, Brasil. \\ *E-mail: thiago.ufra.pa@gmail.com
}

Recebido em fevereiro/2019; Aceito em setembro/2019.

\begin{abstract}
RESUMO: O uso do fogo no manejo da terra é quase onipresente nas propriedades rurais e urbanas na Amazônia após as mudanças climáticas ocorridas nas últimas décadas. Desta forma, objetivou-se nesta pesquisa, analisar a dinâmica temporal dos focos de calor na mesorregião Sudeste paraense entre 2010 e 2017 e, por conseguinte, propor um modelo de pressão-resposta para o atual cenário. Os dados de focos de calor foram adquiridos do satélite AQUA_M-T, a partir do processamento realizado no banco de dados online do Instituto Nacional de Pesquisas Espaciais (INPE) no período compreendido e posteriormente empregado técnicas de SIG para a criação de uma superfície de densidades, utilizando o estimador de Kernel. Os resultados sinalizaram um alerta à mesorregião, em especial aos municípios que fazem parte do arco do desmatamento. $\mathrm{O}$ ano de 2010 teve o maior quantitativo de casos, existindo forte influência de fenômenos como El Niño e de atividades humanas, que foram responsáveis pela maioria das ocorrências de focos. Já os meses com maiores registros foram agosto, setembro e outubro, representando $81 \%$ dos focos referentes ao total registrado, coincidindo com o período do inverno amazônico na região, apontando a conjuntura do agronegócio como responsável pelas modificações ambientais ocorridas nos últimos anos.
\end{abstract}

Palavras-chave: monitoramento ambiental; fogo; alteração no ambiente; Amazônia.

\section{Temporal dynamics of hotspots and their pressure conductors in the Southeastern territory of Pará}

\begin{abstract}
The use of fire in land management is almost omnipresent in rural and urban properties in the Amazon after the climate changes that have occurred in recent decades. Thus, the objective of this research was to analyse the temporal dynamics of the hotspots in the Southeast region of Pará between 2010 and 2017 and, consequently, to propose a pressure-response model for the current scenario. The data of hotspots were acquired from the AQUA_M-T satellite, from the processing performed in the online database of the National Institute of Space Research (INPE) in the period understood and later employed GIS techniques for the creation of a surface of densities, using the Kernel estimator. The results signalled an alert to the mesoregion, especially to the municipalities that are part of the arc of deforestation. The year 2010 had the highest number of cases, with a strong influence of phenomena such as El Niño and human activities, which were responsible for the majority of outbreaks. The months with the highest records were August, September and October, representing $81 \%$ of the outbreaks referring to the total recorded, coinciding with the Amazonian winter period in the region, indicating the agribusiness environment as responsible for the environmental changes that occurred in recent years.
\end{abstract}

Keywords: environmental monitoring; fire; alteration in the environment; Amazon.

\section{INTRODUCÃO}

$\mathrm{O}$ uso do fogo como uma técnica de preparo dos terrenos visando à agricultura é atribuído equivocadamente aos povos tribais de floresta (NOVAIS, 2017). Considerado um agente físico importante, pode levar a perturbações dos ecossistemas e é, ao mesmo tempo, um fenômeno natural e uma criação do homem. Na Amazônia, é possível detectar fogo de ação humana e também fogo de combustão espontânea, que ocorre nos períodos de estiagem, incluindo sinais de fogo e carvão que datam de milhares de anos.

Os incêndios florestais são causados por processos antrópicos e naturais. As ações antrópicas são iniciadas pelo uso do fogo como ferramenta para atingir as mais variadas finalidades, como ampliação das fronteiras de ocupação, convertimento da floresta em lavouras e pastagens, domínio de pragas e expurgação de terreno (TORRES et al., 2017).

Muitos incêndios que ocorrem por causas naturais são, frequentemente, ocasionados por raios e podem ser ecologicamente entendidos como um entre muitos fatores que agem nos ecossistemas naturais. Na América do Norte, países como os Estados Unidos e o Canadá, a maior causa de incêndios florestais é dada como natural, ocasionado por raios. O Canadá, por exemplo, tem $85 \%$ dos seus incêndios ocasionados por relâmpagos. No continente Europeu, a causa principal é a atividade humana, como resultado de questões 
sociais, culturais e políticas, variando conforme as diferenças geográficas (LOURENÇO, 2018).

No Brasil, é comum o uso do fogo para fins como atividades de limpeza e manejo de pastagem, tanto na sua forma primitiva como em sistemas de produção intensivos, atuando na eliminação de resíduos, pragas ou, ainda, na renovação de pastos (HERAWATI; SANTOSO, 2011). O uso do fogo em áreas de pastagens teve início quando pastores perceberam que a vegetação das áreas recentemente queimadas era mais nutritiva e preferida pelos animais, sendo, a partir de então, uma prática rotineira efetuada pela população (COSTA et al., 2017).

Thomaz et al. (2014) afirmam que uma área considerada foco de calor é aquela cuja temperatura está acima de $47^{\circ} \mathrm{C}$ e que geralmente são detectados por satélites de referência, constituindo parte importante do sistema de monitoramento de incêndios florestais. Nesse cenário, o Brasil desponta como líder entre os países da América do Sul em queimadas, demonstrando maior concentração de focos de calor nas regiões Centro-Oeste, Norte e Nordeste. A Amazônia brasileira exibe um histórico de desmatamento desde a década de 1970, com o início da ocupação da região que incentivou um processo migratório e um consequente adensamento urbano (INPE, 2017).

Em 2018, o estado do Pará, situado ao Leste da Região Norte do Brasil, registrou 22.092 focos de calor em todo o seu território, sendo considerado o estado com maior proporção de focos (36\%), seguido por Amazônia (19\%) e Tocantins (13\%) (FONSECA et al., 2019). Atualmente, o Pará é geopoliticamente dividido em seis mesorregiões e há destaque para o Sudeste paraense, por evidenciar altos índices de focos de calor, muito provavelmente devido a incêndios associados à mudança do uso da terra, corroborando o início do povoamento de seus municípios, que, nesse contexto, deu-se a partir da exploração de minérios, ouro, madeira, pecuária intensiva e abertura da nova fronteira agrícola.

De acordo com o IBGE (2010), a mesorregião é formada por 39 municípios que, em sua maioria, possuem fonte econômica primária baseada na exploração de minerais, tais como ferro e níquel, e produção de energia por meio de usinas hidrelétricas, sendo a principal, a priori, situada na cidade de Tucuruí (PA), hoje considerada a quinta maior do mundo e a terceira maior do Brasil em atividade, gerenciada pela Estatal Eletronorte Brasil. Grande parte da energia produzida nessa região é destinada para as demais regiões brasileiras, abastecendo mais de $40 \%$ da população residente em território nacional. Além disso, existe proeminência das atividades de garimpo e extrativismo de madeira, que reduzem a biodiversidade, perturbam os ecossistemas, contribuem com a prevalência de focos de calor e abrem caminhos para outros crimes ambientais.

Mediante essa perspectiva, Assis et al. (2014) comentam que as geotecnologias surgem como um importante recurso de subsídio na assimilação das queimadas, permitindo assim, localizar, quantificar e fazer estudos de análises espaçotemporais das áreas onde ocorrem incêndios. Para os autores, outro recurso pouco contemporâneo é o método DPSIR (Driving Force - Pressure - State - Impact Response), modelo criado na década de 1990 com visão para o desenvolvimento de indicadores ambientais proposto pela Agência Europeia de Meio Ambiente (AEE - European Environmental Agency).
Esse modelo procura, portanto, associar as forças motrizes subjacentes às pressões que estão ocorrendo no meio ambiente, alterando o seu estado. Essas alterações podem causar impactos que necessitam de respostas da sociedade de maneira a modificar ou minimizar o efeito das ações humanas (XIA; LI, 2018).

Assim, com intuito de trazer uma contribuição científica para se estabelecer uma política adequada de prevenção de queimadas, visando à minimização dos impactos causados ao ambiente, o objetivo desta pesquisa foi analisar a dinâmica espaçotemporal dos focos de calor na mesorregião Sudeste do Pará no período de 2010 a 2017, e posteriormente propor para esse cenário, um modelo de pressão-resposta para as atividades de maiores impactos ao ambiente.

\section{MATERIAL E MÉTODOS}

2.1. Área de estudo

A área de estudo foi a mesorregião Sudeste paraense, atualmente composta por 39 municípios circunvizinhos (Figura 1).

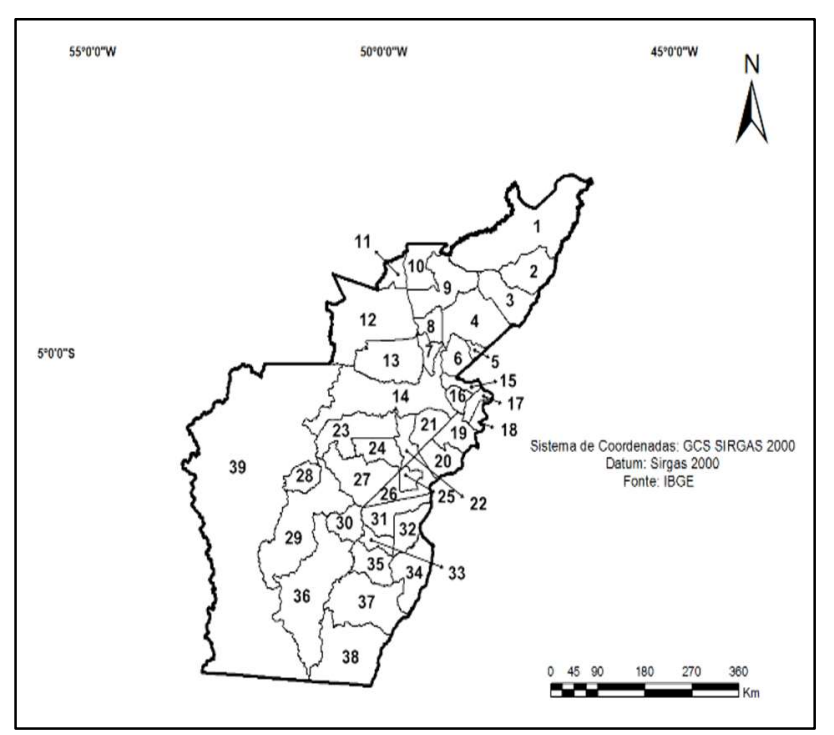

Figura 1. Municípios que compõem a mesorregião Sudeste paraense, Brasil. Fonte: Elaborado pelos autores a partir de dados do IBGE (2010).

Figure 1. Municipalities that make up the southeast region of Paraense, Brazil. Source: Prepared by the authors based on data from IBGE (2010).

Para seleção da área de pesquisa, foram considerados os estudos e relatórios técnicos produzidos pela Fundação Amazônia Paraense de Amparo à Pesquisa (FAPESPA), que identificou, na mesorregião do Sudeste do Pará, municípios com alta densidade populacional e alto risco de focos de queimadas associados aos avanços de áreas desmatadas (Tabela 1), principalmente com ascendência da produção agrícola nos municípios que fazem fronteira com os estados do Tocantins (TO) e Maranhão (MA).

Segundo Bastos (1982), o clima típico da mesorregião de estudo é classificado como Aw, confirmando os mesmos padrões definidos por Köppen-Geiger. Para Hoffmann (2018) e colaboradores, a região está imersa em uma dinâmica climática tropical chuvosa (quente-úmida), com duas estações no ano bem definidas (verão chuvoso e inverno seco), com temperatura média anual do ar de $26^{\circ} \mathrm{C}$. 


\section{Fernandes et al.}

De acordo com o Instituto Nacional de Pesquisas Espaciais - INPE (2017), a mesorregião tem se destacado por evidenciar variações climáticas ao longo do tempo. A priori, a temperatura do ar anual máxima registrada foi $32{ }^{\circ} \mathrm{C}$ e mínima de $22{ }^{\circ} \mathrm{C}$. No estudo por série histórica climática feito por Ishihara et al. (2013), eles observaram que a umidade relativa do ar na região é elevada, expondo oscilações entre as duas estações, com máxima média anual de 78\% e mínima média anual de $32 \%$ já registradas.

Quanto à pluviosidade na região, Soares et al. (2016) confirmaram que o período chuvoso ocorre, notadamente de novembro a maio, e o mais seco de junho a outubro, registrando precipitações médias do mês mais seco inferiores a $60 \mathrm{~mm}$ e do mês mais chuvoso, acima dos $2.100 \mathrm{~mm}$.

Tabela 1. Quantitativo do número de habitantes, área total e percentual de desflorestamento dos municípios pertencentes à mesorregião Sudeste do Pará, Brasil.

Table 1. Number of inhabitants, total area and percentage of deforestation of the municipalities belonging to the mesoregion Southeast of Pará, Brazil.

\begin{tabular}{|c|c|c|c|}
\hline Municípios do Sudeste do Pará (Brasil) & $\begin{array}{l}\text { Número de habitantes } \\
\text { (mil) }\end{array}$ & $\begin{array}{c}\text { Área total } \\
\left(\mathrm{Km}^{2}\right)\end{array}$ & $\begin{array}{c}\text { Desflorestamento } \\
\text { até } 2017(\%)\end{array}$ \\
\hline 1 - Paragominas & 97.819 & 19.465 & $8773.3(6,3)$ \\
\hline 2 - Ulianópolis & 43.341 & 5.122 & $3539.8(2,5)$ \\
\hline 3 - Dom Eliseu & 51.319 & 5.296 & $3489.2(2,5)$ \\
\hline 4 - Rondon do Pará & 46.964 & 8.286 & $5572.2(4,0)$ \\
\hline 5 - Abel Figueiredo & 6.780 & 616 & $566.7(0,4)$ \\
\hline 6 - Bom Jesus do Tocantins & 15.298 & 2.827 & $1774.9(1,3)$ \\
\hline 7 - Nova Ipixuna & 14.645 & 1.569 & $1160.4(0,8)$ \\
\hline 8 - Jacundá & 51.360 & 2.013 & $1475.6(1,1)$ \\
\hline 9 - Goianésia do Pará & 30.436 & 7.048 & $3885.5(2,8)$ \\
\hline 10 - Breu Branco & 52.493 & 3.953 & $2821.3(2,0)$ \\
\hline 11 - Tucuruí & 97.128 & 2.095 & $815.8(0,6)$ \\
\hline 12 - Novo Repartimento & 62.050 & 15.432 & $7954.2(5,7)$ \\
\hline 13 - Itupiranga & 51.220 & 7.901 & $4880.4(3,5)$ \\
\hline 14 - Marabá & 233.669 & 15.161 & $8675.4(6,2)$ \\
\hline 15 - São João do Araguaia & 13.155 & 1.288 & $936.0(0,7)$ \\
\hline 16 - São Domingos do Araguaia & 23.130 & 1.397 & $1294.4(0,9)$ \\
\hline 17 - Brejo Grande do Araguaia & 7.317 & 1.292 & $1069.8(0,8)$ \\
\hline 18 - Palestina do Pará & 7.475 & 985 & $826.8(0,6)$ \\
\hline 19 - São Geraldo do Araguaia & 25.587 & 3.181 & $2502.6(1,8)$ \\
\hline 20 - Piçarra & 12.697 & 3.322 & $2924.6(2,1)$ \\
\hline 21 - Eldorado dos Carajás & 31.786 & 2.968 & $2750.7(2,0)$ \\
\hline 22 - Curionópolis & 18.288 & 2.375 & $2060.8(1,5)$ \\
\hline 23 - Parauapebas & 15.3908 & 6.968 & $1324.3(1,1)$ \\
\hline 24 - Canaã dos Carajás & 26.716 & 3.156 & $1744.0(1,3)$ \\
\hline 25 - Sapucaia & 5.047 & 1.300 & $1163.5(0,8)$ \\
\hline 26 - Xinguara & 40.573 & 3.793 & $3379.0(2,4)$ \\
\hline 27 - Água Azul do Norte & 25.057 & 7.125 & $4660.4(3,3)$ \\
\hline 28 - Tucumã & 33.690 & 2.513 & $2293.8(1,6)$ \\
\hline 29 - Ourilândia do Norte & 27.359 & 1.4357 & $1712.2(1,2)$ \\
\hline $30-$ Bannach & 3.431 & 2.964 & $2193.1(1,6)$ \\
\hline 31 - Rio Maria & 17.697 & 4.122 & $3407.0(2,4)$ \\
\hline 32 - Floresta do Araguaia & 17.768 & 3.454 & $1920.6(1,4)$ \\
\hline 33 - Pau D’Arco & 6.033 & 1.674 & $938.9(0,7)$ \\
\hline 34 - Conceição do Araguaia & 45.557 & 5.847 & $3089.1(2,2)$ \\
\hline 35 - Redenção & 75.556 & 3.830 & $2663.0(1,9)$ \\
\hline 36 - Cumaru do Norte & 10.466 & 17.105 & $7337.7(5,3)$ \\
\hline 37 - Santa Maria das Barreiras & 17.206 & 10.351 & $5938.0(4,3)$ \\
\hline 38 - Santana do Araguaia & 56.153 & 11.609 & $7238.5(5,2)$ \\
\hline 39 - São Felix do Xingu & 91.340 & 84.253 & $18440.1(13,2)$ \\
\hline Total & 1.647 .514 & 298.013 & $139.196,6(100)$ \\
\hline
\end{tabular}

\subsection{Procedimentos metodológicos}

Os dados utilizados nesta pesquisa são procedentes das plataformas website BDMEP - Banco de Dados Meteorológicos para Ensino e Pesquisa, do Instituto Nacional de Meteorologia, do Bdqueimadas - Banco de Dados de Queimadas, do Centro de Previsões de Tempo e Estudos Climáticos - CPTEC e do Observatório da Terra - Projeto Piloto PRODES, instituído pelo Programa de Monitoramento da Floresta Amazônica Brasileira por Satélite. Atualmente, todos os websites estão acoplados no site institucional do INPE.

Os dados sobre números de áreas desmatadas e taxas de desmatamento foram procedentes do Projeto PRODES, que foi implementado ainda na década de 1980 com o objetivo de realizar o monitoramento por satélite do desmatamento por corte raso na Amazônia Legal e que produz taxas anuais de desmatamento na região, usadas para subsidiar pesquisas no ramo da ciência e para o estabelecimento de políticas públicas pelo governo brasileiro.

Os dados de focos de calor foram adquiridos a partir do processamento diário das imagens termais do sensor MODIS (Moderate Resolution Imaging Spectrodiometer), atrelado ao satélite AQUA_M-T, atualmente considerado referência pelo INPE, em virtude de os dados corresponderem às informações geradas no período da manhã (passagem das 4h GMT) e da tarde (passagem das 17h GMT), corroborando com a análise 
de números de focos para as regiões brasileiras (INPE, 2018). Após esses ritos, os dados, por sua vez, foram extraídos de forma gratuita e simultânea, por ano, em formato shapefile.

Em seguida, para identificar os principais agentes causadores do fator de pressão-mudança no ambiente, foram selecionados estudos hodiernos internacionais e nacionais, como o de Martins (2016) e Santana et al. (2018), que obtiveram resultados promissores em suas intervenções científicas utilizando o modelo DPSIR e outras ferramentas acuradas, a priori, com missão de identificar forças que empurram espontaneamente o desmatamento no território da Amazônia Legal brasileira.

\subsection{Interpretações dos dados}

Os dados sobre focos de calor, ainda em formato shapefiles, foram alinhados e sobrepostos à área de estudo, organizados em uma única base. Essa manipulação foi necessária visto a praticidade e os ajustes nas devidas camadas, facilitando o procedimento de interpretação das informações e geração de dados procedidos sazonais (anos e meses) dos focos de calor (2010-2017). Todo o processamento feito com os dados foi realizado no software livre QGIS, versão 3.4.

Após a sobreposição dos dados de focos de calor sobre os limites territoriais da mesorregião, dados matriciais de densidade de focos de calor, aglomerados para o período de estudo, foram acurados por meio do algoritmo estimador de densidade de Kernel.

Nesse estudo, as densidões de Kernel foram exaladas em 5 classes, sendo: muito baixa, baixa, média, alta e muito alta, seguindo o modelo de legenda aplicado por Lopes et al. (2017) em um estudo que monitorou focos de calor de 2010 e 2015 para a cidade de Novo Progresso (PA) e por Fernandes et al. (2018), que aplicaram a mesma metodologia e classificação em um estudo de avaliação de impacto ambiental para a cidade de Parauapebas, situada na região Sudeste da Amazônia paraense, Brasil.

Desta forma, diante das inúmeras pesquisas contemporâneas, escolheu-se nomear o algoritmo estimador de densidade de Kernel, por ser um indicador de fácil uso, interpretação e comparação.

\section{RESULTADOS}

3.1. Principais agentes causadores de pressão ambiental

Muitas são os fatores, apontadas pela literatura pertinente, acerca das causas de pressão no ambiente, em especial, da Amazônia Legal brasileira. Desde aspectos endógenos como as condições edafo-climáticas, a aspectos relacionados à ação antrópica como os movimentos populacionais, o crescimento urbano e as ações autônomas ou induzidas dos diversos agentes econômicos públicos e privados que têm atuado na região, configurando historicamente os processos de ocupação do solo e aproveitamento econômico do espaço amazônico.

Com a breve revisão sistemática, descobriu-se que os principais agentes causadores de pressão de mudança no ambiente estão associados com as ocorrências de incêndios florestais na mesorregião, grosso modo, a intervenção humana associada à formação agropolítica, inseridas em ações como limpeza de áreas agrícolas, pastagens para manejo de gado, extração de produtos florestais não madeireiros, desenvolvimento industrial, principalmente, com consolidações de novos empreendimentos minerais e ferroviários, crescimento de empresas metalúrgicas para prestação de serviços e reassentamento em área rural e caça, alterando marcadamente diferentes municípios de médio e grande porte econômico.

Salienta-se que houve a ocorrência do fenômeno El Niño com particularidades diferenciadas, em especial para a Amazônia paraense e em alguns anos do período examinado, mais especificamente: 2010 (moderada intensidade) e 20152016 (forte intensidade), conforme divulgado em boletim oficial pelo INPE (2018).

Conforme Silva et al. (2018), eventos de El Niño são caracterizados por aquecimento anormal no Oceano Pacífico equatorial, influenciando as condições climáticas globais em períodos irregulares. A ocorrência desse evento afeta com proporcionalidade o regime de chuvas em regiões tropicais, interferindo nos padrões pluviométricos devido ao prolongamento do período de estiagem, deixando as florestas mais susceptíveis a riscos de incêndios.

Para efeitos de sazonalidades, os meses que evidenciaram variações climáticas coincidiram com a prevalência de focos de calor, o que, neste caso, corroborou com a classificação climática estimada por Köppen e colaboradores. Não foram contabilizadas áreas desmatadas para a mesorregião Sudeste do Pará devido à falta de manutenção e defasagem do banco de dados.

Por fim, observou-se que as dessemelhantes capacidades econômicas de "bem viver" de cada município intervieram para a implementação de projetos e programas de gerenciamento e fiscalização de queimadas, a priori para municípios onde se mantêm áreas de proteção permanente (APP) e áreas florestais como patrimônio ecológico da nação brasileira.

\subsection{O caso da Mesorregião Sudeste paraense}

A Figura 2 apresenta o número total de focos de calor no Sudeste paraense e de áreas queimadas $\left(\mathrm{km}^{2}\right)$, na Amazônia Legal e no Brasil, prioritariamente para o período pesquisado.

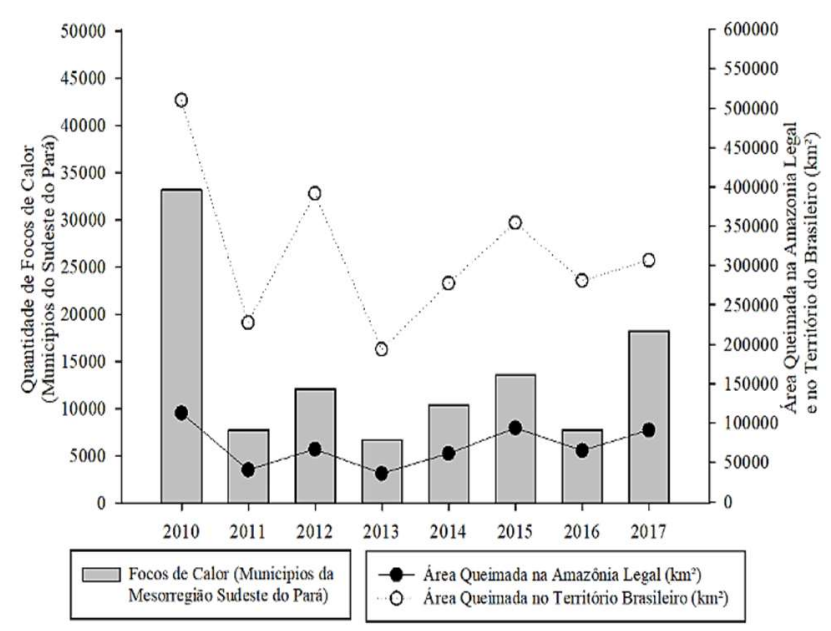

Figura 2. Número total de focos de calor registrados na mesorregião Sudeste paraense e de área queimada na Amazônia Legal e no Brasil entre o período de 2010-2017. Fonte: Elaborado pelos autores a partir de dados do INPE (2018) e PRODES (2018).

Figure 2. Total number of heat sources recorded in the southeast region of Paraense and burned area in the Legal Amazon and in Brazil between the period 2010-2017. Source: Prepared by the authors based on data from INPE (2018) and PRODES (2018).

No ano de 2010, registrou-se 33.169 ocorrências de focos de calor na mesorregião Sudeste, representando 30,23\% em relação aos registros totais. No mesmo ano, foram 
contabilizados $112.814 \mathrm{~km}^{2}$ de área desmatada em toda a Amazônia Legal, promulgando um percentual de 19,87\%. Ainda no ano em questão, o Brasil contabilizou $510.116 \mathrm{~km}^{2}$ de área desmatada, um percentual de $20,06 \%$, com uma taxa de desmatamento de $3,77 \%$, sendo considerada a mais alta na janela temporal de análise neste estudo.

O segundo ano com maior registro anual de focos de calor foi em 2017, com 18.210 focos, representando $16,6 \%$ do total geral registrado. Em consonância, no mesmo ano, foram contabilizados $91.240 \mathrm{~km}^{2}$ de área queimada na Amazônia Legal (16\%) e $306.993 \mathrm{~km}^{2}$ (12\%) de área queimada no Brasil. Nesse estudo, observou-se que no período de 2010 ocorreram os maiores registros de focos de calor, coincidindo com o ano de ocorrência do El Niño, que foi avaliado, segundo o INPE (2018), como de moderada intensidade.

No Brasil, o Sistema de Alerta de Desmatamento (SAD) identificou que, em março de 2018, foram desmatados $287 \mathrm{~km}^{2}$ (28.700 ha) na Amazônia Legal. A fração de desmatamento entre 1 e 10 hectares foi de $18 \%$ do total detectado (4.400 ha). Considerando somente os alertas a partir de 10 hectares, houve aumento de $249 \%$ em relação a março de 2017 , quando o desmatamento somou $71 \mathrm{~km}^{2}$ (7.100 ha). Em março de 2018, o desmatamento ocorreu em Mato Grosso (40\%), Roraima (21\%), Amazonas (14\%) e Rondônia (7\%).

Esse cenário, regado por uma insegurança política, apontou para uma evolução do desmatamento florestal no estado do Pará, que chegou a expor um crescimento de $18 \%$ de área desmatada no mesmo período, equivalente a $52 \mathrm{~km}^{2}$ (5.200 ha), em relação aos desmontes que ocorreram nos estados que constituem a Amazônia Legal. Assim, integra-se a esse estudo um mapeamento dos focos de calor registrados na mesorregião Sudeste paraense, confrontando-os com as áreas desmatadas no estado do Pará e no Brasil, entre 20102017, conforme Figura 3.

Como corroborado anteriormente, a média anual de focos de calor registrados na mesorregião foi de 13.714 ocorrências.
Em comparativo a esse panorama, o desmatamento médio anual de florestas no estado do Pará foi de $256.505 \mathrm{~km}^{2}$, com taxa média anual de 3\%. Já no que se refere ao Brasil, a média anual de desmatamento foi de $761.950 \mathrm{~km}^{2}$, com uma taxa anual de $6 \%$ para o mesmo período.

Com o viés de comparar a conjuntura de eventos de focos de calor registrados, foi fácil quantificar e associar os focos de calor, que eram previsíveis, exibindo-os em diversos cenários (Tabela 2) sendo, em nível de estado (Pará), de região brasileira (Norte), de país (Brasil) e de continente (Sul Americano).

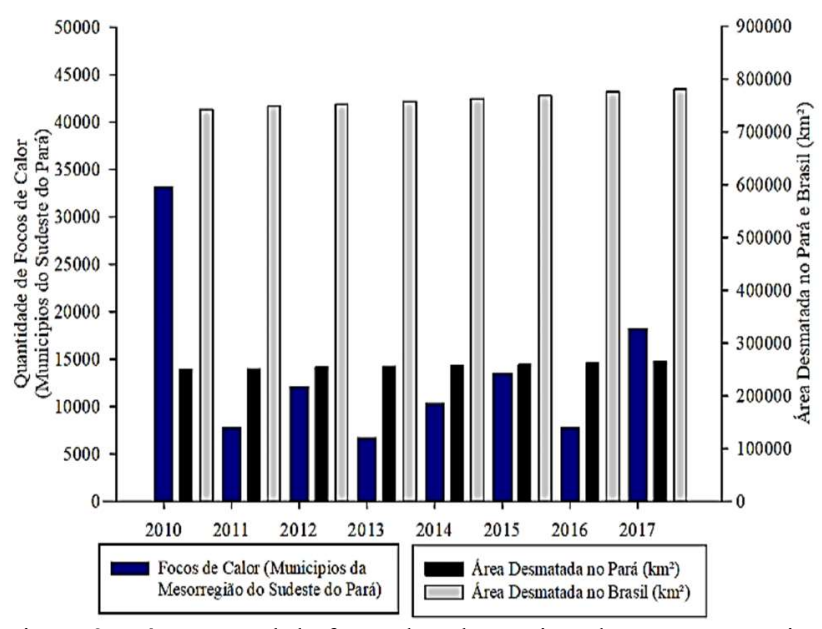

Figura 3. Número total de focos de calor registrados na mesorregião do Sudeste paraense e de área desmatada no estado do Pará e Brasil entre 2010 e 2017. Fonte: Elaborado pelos autores a partir de dados do INPE, DETER e PRODES (2018).

Figure 3. Total number of heat sources recorded in the mesoregion of Southeast Pará and deforested area in the State of Pará and Brazil between 2010 and 2017. Source: Prepared by the authors based on data from INPE, DETER and PRODES (2018).

Tabela 2. Número total de focos de calor (em mil) registrados na mesorregião Sudeste paraense, no estado do Pará, Região Norte, Brasil e América do Sul, entre o período de 2010-2017.

Table 2. Total number of hotspots (in thousands) registered in the Southeast region of Pará, in the state of Pará, North Region, Brazil and South America, between the period of 2010-2017.

\begin{tabular}{cccccc}
\hline Anos & $\begin{array}{c}\text { Mesorregião } \\
\text { Sudeste do Pará }\end{array}$ & $\begin{array}{c}\text { Estado Federativo } \\
\text { do Pará }\end{array}$ & $\begin{array}{c}\text { Região Norte do } \\
\text { Brasil }\end{array}$ & Brasil & $\begin{array}{c}\text { América } \\
\text { do Sul }\end{array}$ \\
\hline 2010 & 33.169 & 57.214 & 127.057 & 319.503 & 525.074 \\
2011 & 7.789 & 26.573 & 54.412 & 158.180 & 299.580 \\
2012 & 12.133 & 37.231 & 82.369 & 217.336 & 349.505 \\
2013 & 6.747 & 24.056 & 53.060 & 128.232 & 266.097 \\
2014 & 10.367 & 35.537 & 74.761 & 175.993 & 282.580 \\
2015 & 13.556 & 43.184 & 96.634 & 216.881 & 334.375 \\
2016 & 7.739 & 29.731 & 81.082 & 184.364 & 339.102 \\
2017 & 18.210 & 49.772 & 98.299 & 207.633 & 346.068 \\
\hline Total & 109.710 & 303.298 & 667.674 & 1.608 .122 & 2.742 .381 \\
\hline Média & 13.714 & 37.912 & 83.459 & 201.015 & 342.797 \\
\hline
\end{tabular}

Fonte: Elaborado pelos autores a partir dos dados do INPE (2018).

$\mathrm{Na}$ análise descritiva, a média anual de focos de calor na abrangência estadual foi de 37.912, na região Norte (83.459), no Brasil (201.015) e na América do Sul (342.797), com destaque para o ano de 2010 como o de maior registro de ocorrências. Para tanto, nesse ano, foram contabilizados 33.169 focos na mesorregião Sudeste paraense, correspondendo a $30,23 \%$ do total de focos entre 2010-2017, seguidos de 127.057 na região Norte (19,03\%), 319.503 no
Brasil (19,87\%) e 525.074 na América do Sul (19,15\%), conforme corroborado pelo INPE (2018).

Quanto à América do Sul, o total de focos de calor entre 2010-2017 foi de 2.742.381 de registros. Países como Argentina, Bolívia e Brasil se destacam com as maiores estatísticas de focos desde a década de 1990 que, para Torres et al. (2017), possui maior predominância de acontecimentos em períodos de inverno, devido a constituir variações 
climáticas que interferem na dinâmica da temperatura do ar, da umidade relativa do ar e da pluviosidade em diversas formas e diferentes localidades.

3.3. Sazonalidades de focos de calor na mesorregião Sudeste do Pará

A espacialização temporal dos focos de calor na área fisiográfica correspondente à mesorregião Sudeste paraense está exposta na Figura 4. Ao realizar a sobreposição dos dados de focos de calor na janela temporal de 8 anos, foram identificados um total 109.710 , com média anual de 13.714 registros. $\mathrm{Na}$ análise geral, os anos com maiores números de focos de calor foram 2010, com exatos 33.169 (30,23\%), seguido por 2017 com 18.210 (16,6\%); inversamente, os anos de 2013 e 2016 contabilizaram os menores números de focos, sendo $6.747(6,15 \%)$ e $7.739(7,05 \%)$ em relação ao total geral de registros.
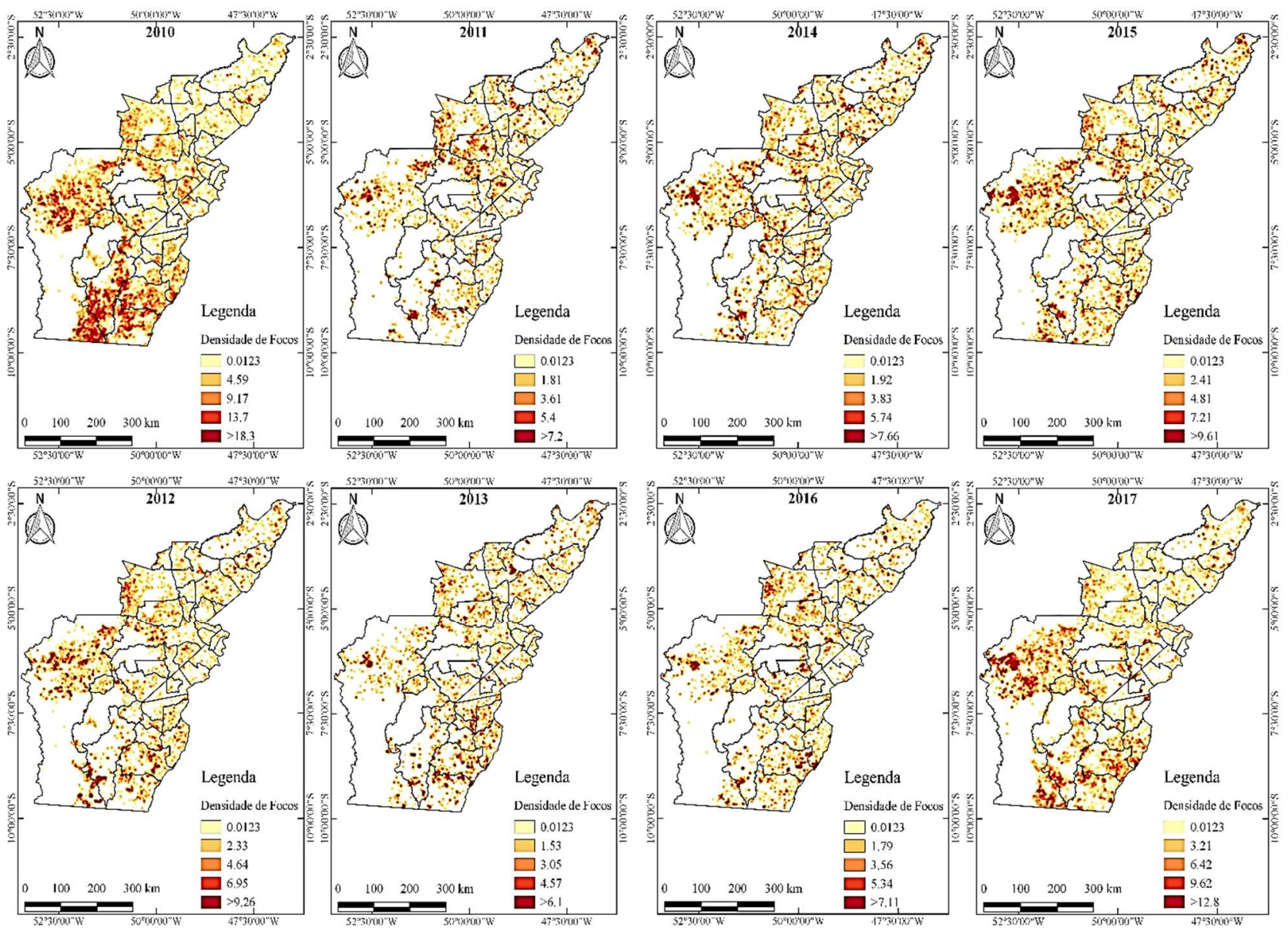

Figura 4. Mapas de densidade dos focos de calor detectados pelos sensores do satélite AQUA_M-T para os anos de 2010 a 2017 , na região Sudeste do Pará, Brasil. Fonte: Elaborado pelos autores a partir dos dados do INPE (2018).

Figure 4. Density maps of hotspots detected by AQUA_M-T satellite sensors for the years 2010 to 2017, in the Southeast region of Pará, Brazil. Source: Prepared by the authors based on data from INPE (2018).

Segundo o INPE (2018), no ano de 2010 foi constatado evento de El Niño de intensidade moderada e em 2016, de intensidade forte. Contudo, a ocorrência de poucos focos de calor em um ano atípico de El Niño de forte intensidade é perceptível devido aos investimentos do Governo Federal em planejamento e monitoramento ambiental, a priori, com o lançamento da terceira fase do Plano de Ação para Prevenção e Controle do Desmatamento na Amazônia Legal (PPCDAm), que em 2016 se consagrou como um instrumentos fundamental para a implementação da Política Nacional sobre Mudança do Clima (PNMC, Lei $\mathrm{n}^{0} 12.187 / 2009$ ), que tem como foco principal a mitigação das emissões de gases de efeito estufa relacionadas ao uso da terra, mudança do uso da terra e florestas (MELLO; ARTAXO, 2017). Os autores complementam que as ações de maior impacto na queda do desmatamento partiram do eixo Monitoramento e Controle, estando bastante associadas ao desenvolvimento do Sistema
Deter e ao planejamento integrado da fiscalização, cobrindo 90\% do território da Amazônia.

Notoriamente, essas oscilações anuais contribuem com as mudanças no clima, expondo o ambiente a sucessíveis eventos de queimadas e, por consequência, ocasionando alterações na dinâmica da paisagem.

A hipótese de que a frequência e a intensidade dos incêndios florestais irão aumentar em função do aquecimento global exigirá ações integradas de prevenção e combate a incêndios florestais para minimizar possíveis danos ambientais, sociais e econômicos (ARTAXO et al., 2014).

Diante dos fatos, entre os anos de 2010-2017, os municípios que registraram os maiores números de focos de calor (acima de 3.000 focos) foram São Felix do Xingu, com 30.537 (27,83\%), Cumaru do Norte, com 9.110 (8,30\%), Santa Maria das Barreiras, com 7.493 (6,83\%), Santana do Araguaia, com 6.359 (5,80\%), Novo Repartimento, com 6.316 (5,76\%), 
Marabá, com 5.902 (5,38\%), Paragominas, com 4.769 (4,35\%), Itupiranga, com $683(3,36 \%)$ e, por fim, Conceição do Araguaia, com exatos 3.322 (3,03\%) em relação ao total geral registrado.

$\mathrm{Na}$ mesma linha indutiva, os municípios com menores números de focos de calor (abaixo de 500 focos) foram: Palestina do Pará, com 129 (0,12\%); Abel Figueiredo, com 248 (0,23\%); Sapucaia, com 249 (0,23\%); Brejo Grande do Araguaia, com 292 (0,27\%); São Domingos do Araguaia, com $324(0,30 \%)$ e Jacundá, com $362(0,33 \%)$ do total geral de registros. Em vista de todo esse cenário, são apresentadas na Figura 5, as variações anuais referentes as cinco classes de adensamento de focos.

Dito isso, observa-se que as classes de densidades intituladas como média, alta e muito alta se sobressaíram em todos os anos analisados, assinalando riscos potenciais de incêndios florestais, principalmente em municípios que fazem parte do arco do desmatamento na Amazônia e daqueles constituintes a chamada nova fronteira agrícola do Brasil.

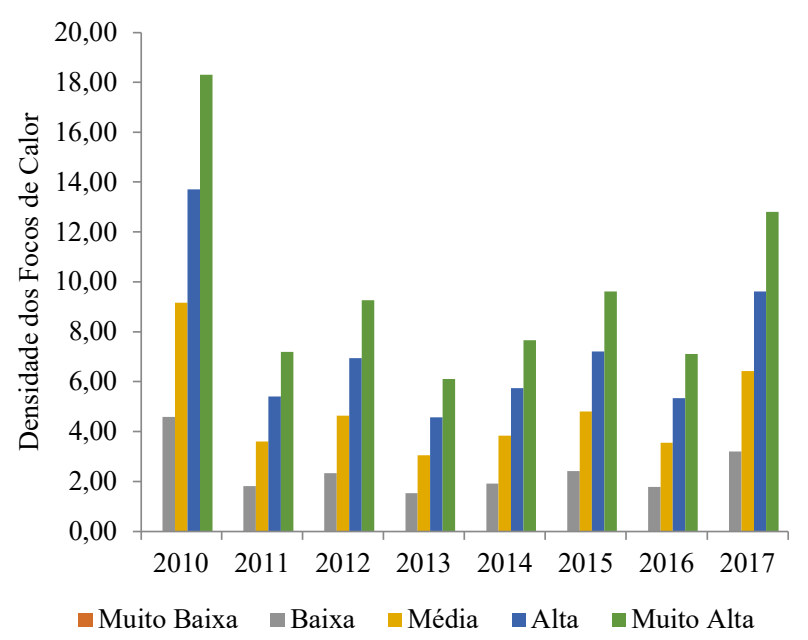

Figura 5. Variação anual das classes de densidade dos focos de calor detectados pelos sensores do satélite AQUA_M-T para os anos de 2010 a 2017, mesorregião Sudeste do Pará (PA). Fonte: Elaborado pelos autores a partir de dados do INPE (2018).

Figure 5. Annual variation of the density classes of the heat sources detected by the AQUA_M-T satellite sensors for the years 2010 to 2017, Southeast region of Pará (PA). Source: Prepared by the authors based on data from INPE (2018).

Ao analisar o cenário em estudo, separadamente e por anos, observa-se uma dinâmica sazonal incorporada pelos anos de 2010, 2012, 2014, 2015 e 2017, que respondem por um incremento das densidades de focos de calor onipresentes em todas as classes.

Contudo, os anos 2011, 2013 e 2016 foram susceptíveis a uma redução dos focos de calor, o que reforça a afirmativa de que as manchas de densidades Alta e Muito Alta amortizaram consideravelmente, tendo o ano de 2011 registrado evento $L a$ Niña de intensidade moderada, com registros de chuvas na mesorregião com média entre 1.900 a 2.100 mm/ano (INMET, 2017). Desta forma, também são apresentadas as sazonalidades dos números de focos de calor total, por mês e ano, conforme mostra a Figura 6.

Compete destacar que a sazonalidade nessa série temporal está devidamente relacionada com as estações do ano, que, nessa conjunção, estão também associadas ao ciclo climático da Amazônia, sendo: quente-úmida ou verão chuvoso (novembro-abril) e quente-seca (junho a outubro), que, por sua vez, exibe um comportamento climático na região típico de inverno seco. Percebeu-se que os meses com maiores frequências de registros de focos de calor foram agosto, com 31.202 , representando $28,44 \%$ em relação ao total de focos registrados; setembro, com 42.085 (38,36\%); e outubro, com $14,70 \%$ referente ao total registrado.

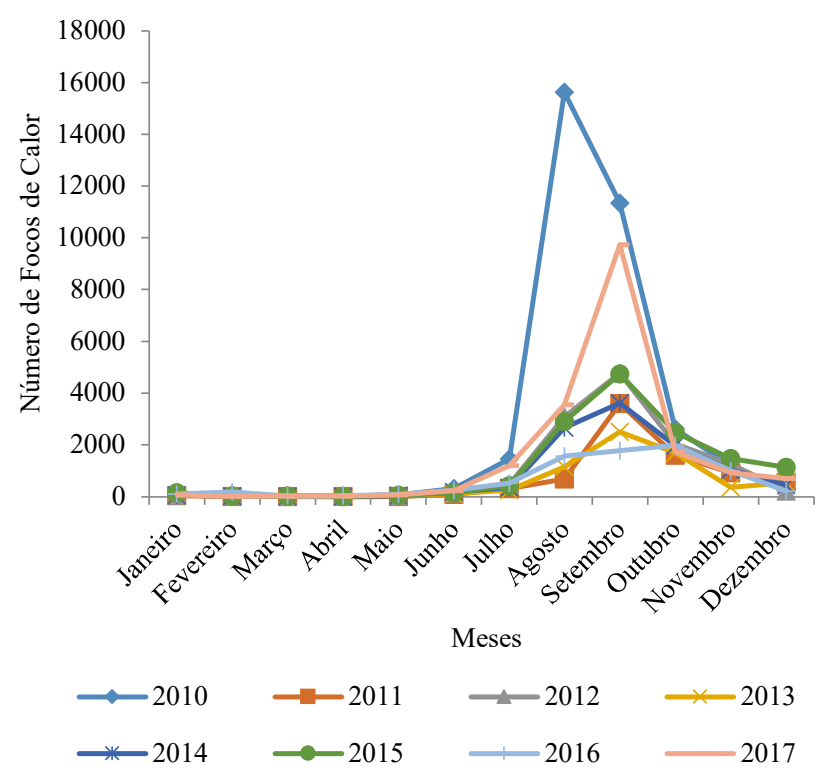

Figura 6. Número de focos de calor distribuídos por mês e ano na mesorregião Sudeste paraense, Brasil. Fonte: Elaborado pelos autores a partir de dados do INPE (2018).

Figure 6. Number of heat sources distributed per month and year in the southeast region of Paraense, Brazil. Source: Prepared by the authors based on data from INPE (2018).

Práticas de fogo por ação antrópica são mais comuns no bioma amazônico, entretanto, em estudos feitos por Assis et al. (2014), foi evidenciado que há uma sazonalidade e um sinergismo entre o clima, o desmatamento e os incêndios. Segundo os autores, as ocorrências de queimadas são mais frequentes durante a estação seca, nos meses de junho a setembro, e ela pode ser intensificada com o desmatamento, no qual os agricultores disparam fogo ao material seco que fica no solo proveniente de atividades madeireiras.

Em se tratando do ciclo hidrológico, salienta-se a importância da atuação das florestas na Amazônia para garantia da distribuição das chuvas em todo o Brasil. Nesse ponto, percebe-se que os menores registros de focos de calor estão associados com a baixa pluviosidade na mesorregião Sudeste. Os meses com menores números de focos foram fevereiro, com 356 registros, exibindo um percentual de $0,32 \%$, seguido dos meses de março e abril com 127 e 128 focos, ambos representando $(0,12 \%)$ e, por fim, maio, com 387 focos, exatos $(0,35 \%)$ do total registrado.

Esse evento climático converge com a mesma estação climática para a região da Amazônia, o que revela a importância dos ciclos biogeoquímicos para a regulação dos ecossistemas, bem como da acuidade das florestas para a estabilização das variações climáticas, minimizando agravos com as queimadas e com a própria saúde humana. 
3.4. Impulsores de pressão de mudanças na dinâmica territorial da mesorregião Sudeste da Amazônia paraense

Estudos mais robustos, com características de abrangência macrorregional, apontam a mesorregião Sudeste como o maior polo industrial paraense, impulsionada pelo ascensionário crescimento econômico da atividade mineradora e metalúrgica. Segundo Artaxo et al. (2014), o estado do Pará representa mais de $60 \%$ da produção de minérios no Brasil, assegurando no ranking sete empresas das vinte e cinco maiores produtoras desta matéria-prima.

No estudo desenvolvido por Hoffmann et al. (2018) sobre a conjuntura das causas do desmatamento na Amazônia, considerou-se a formação do polo do agronegócio como o eixo propulsor dos inúmeros desmontes em áreas de combate ao desflorestamento, principalmente nas mesorregiões do Sudeste e Baixo Amazonas paraense. Para o autor, a incorporação desse polo gera desfechos como a expansão da fronteira agrícola, que, atualmente, é o maior fator de pressão de mudanças na paisagem amazonense.

Oliveira; Piffer (2017), comentam que a ocupação urbana provoca uma força motriz e pressão no solo, gerando zonas urbanas intrarregionais, resultante da concentração da população aglomerada, causando graves problemas socioambientais. Posto isso, visando a construção de um modelo DPSIR para a mesorregião Sudeste, foram conceituados os principais fatores de relevância e importância, assim, estabelecendo o sincronismo ditado ao estimar os Drives, Pressão, Estado, Impactos e as Respostas, conforme ilustrado na Figura 7.

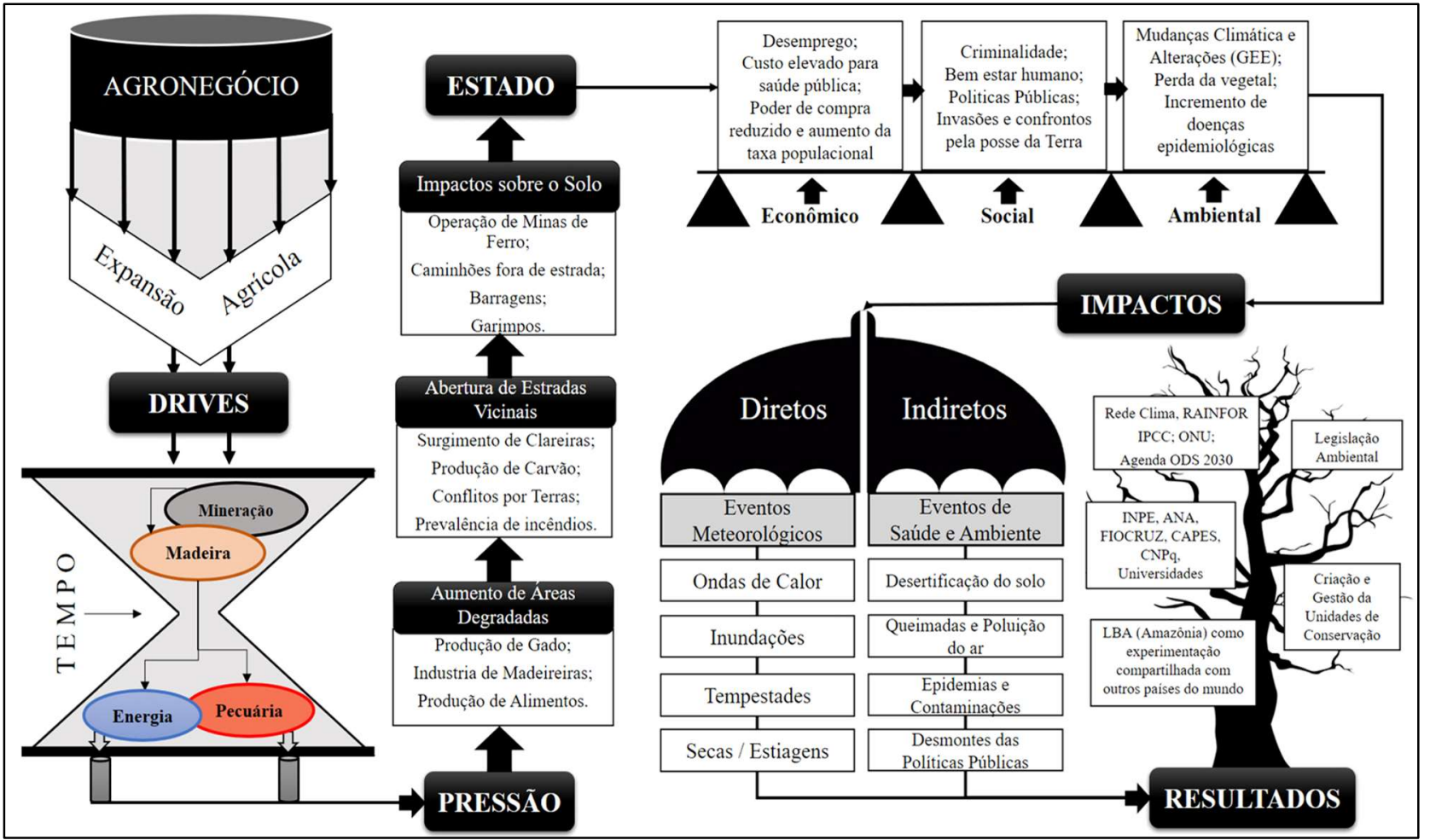

Figura 7. Modelo de DPSIR para caso da mesorregião do Sudeste Paraense. Fonte: Elaborado pelos autores (2018).

Figure 7. DPSIR model for the case of the Southeast Pará mesoregion. Source: Prepared by the authors (2018).

A busca pelo equilíbrio entre o crescimento econômico e a manutenção dos recursos naturais tem, nos últimos anos, fortalecido o paradigma do desenvolvimento sustentável. Diversos estudos foram desenvolvidos a fim de verificar empiricamente o processo de desmatamento. Os principais recortes identificados na literatura são: 1) desmatamento ligado a questões de mercado ou decisão de investimento; 2) os que investigam o desmatamento pela ótica dos pequenos produtores; 3) aqueles que associam o desmatamento ao tamanho dos estabelecimentos agrícolas e formação do agronegócio; 4) os que buscam identificar como as instituições e os direitos de propriedade afetam o desmatamento e 5) os que consideram o papel das políticas públicas como motivador do desmatamento (SANTANA et al., 2018).

Portanto, o modelo DPSIR elaborado considera que as atividades econômicas e a conduta humana afetam as condições ambientais e de bem-estar. Diante disso, o modelo em potencial avigora a interação entre as causas macros dos problemas ambientais, os impactos susceptíveis e as respostas da sociedade, de uma forma integrada e sistêmica, evidenciando dentro desse panorama, tido como de desenvolvimento, a vulnerabilidade dos diversos grupos sociais.

\section{DISCUSSÃO}

Estudos internacionais indicam que na Europa, países localizados ao Sul são anualmente atingidos pelas queimadas, que contam com as variações extremas advindas do Norte e do Leste do continente. Em 2018, Portugal subiu também ao topo dos países com maior quantidade de áreas incendiadas. Segundo dados do Sistema Europeu de Informação de Incêndios Florestais (EFFIS), o incêndio florestal acarretado na Vila de Monchique, no distrito de Faro, região do Algarve, destruiu cerca de 28.500 hectares, mais da metade dos 41 mil hectares que foram queimados na mesma região em 2003, sobretudo nos arredores de Portimão, Aljezur e Lagos. Todavia, segundo dados do Instituto da Conservação da Natureza e das Florestas (ICNF) do país, esse valor já supera 
cerca de 21 mil hectares registrados na Suécia e os 18 mil no Reino Unido.

$\mathrm{Na}$ América do Norte, países como Estados Unidos, por exemplo, possuem uma estatística histórica de grandes e intensos incêndios florestais. A título de exemplo, considerase a tragédia de 1999, incidida no estado da Califórnia, localizada na região dos Estados do Pacífico, onde foram queimadas 280 casas em uma média de três horas, com cerca de 120 novos focos de incêndios por dia, três anos depois. Pela primeira vez na história dos EUA, foi gasto US\$ 1 bilhão em supressão, com aproximadamente 25 mil bombeiros, 900 motores, 155 helicópteros, 54 petroleiros e 31 cozinhas móveis (SILVA et al., 2018).

As causas dos incêndios, além de diferirem de país para país, são também espacialmente diferentes dentro do mesmo país, pois dependem de um conjunto específico de fatores regionais, associados não só aos componentes ambientais, como as condições climáticas, o relevo, as características dos combustíveis, entre outras, mas, também, às atitudes e aos comportamentos humanos.

Segundo Davidson et al. (2012), a queima de biomassa florestal está entre os principais contribuintes mundiais para a emissão de poluentes atmosféricos, incluindo os gases de efeito estufa e material particulado, resultando, em muitos casos, na exposição humana a elevados níveis de poluentes do ar, originados por focos de incêndio deliberados, principalmente, em áreas de exploração de minérios e madeira nativa.

Os municípios que compõem geograficamente a mesorregião Sudeste paraense disponibilizam dados acurados de focos de calor com uma janela temporal disposta com mais de 30 anos de informações, confirmando fomento no sistema de informação espaciais.

O estado do Pará, considerado parte de uma nova fronteira agrícola, expõe ascendência quanto aos números de áreas desflorestadas. Na janela temporal deste estudo, dados do sistema PRODES informaram que o Pará registrou um total de $2.052 .048 \mathrm{~km}^{2}$ de áreas desmatadas e o ano de maior registro desse processo foi em 2017, contabilizando cerca de 264.691 $\mathrm{km}^{2}$, assertiva que representa uma taxa de $2,43 \%$ de deflorestação.

No território brasileiro, o mesmo sistema de informação registrou um total de $6.095 .605 \mathrm{~km}^{2}$ de áreas florestais desmatadas. $\mathrm{O}$ ano de maior registro também foi 2017, com $780.960 \mathrm{~km}^{2}$ de áreas desmatadas, com uma taxa de desmatamento de $6,9 \%$ para o mesmo ano.

No que tange à realidade brasileira, o estado do Pará é uma das Unidades Federativas que apresenta, ano a ano, aumentos sucessivos de focos de calor, principalmente associados ao desmatamento na Amazônia. Nesse ponto, observa-se que a mesorregião Sudeste registrou números alarmantes entre 2010-2017, principalmente, concentrando manchas de densidade Alta e Muito Alta em municípios mais situados ao Sul e Nordeste.

Ressalva-se maior concentração de manchas de densidade na escala Alta e Muito Alta em municípios situados ao Sul e a Oeste da mesorregião, devido ao processo histórico do desmatamento na região, levando a uma rápida mudança no uso e ocupação de terras, em especial em área estritamente composta por reservas indígenas, como é o caso do Parque Indígena do Xingu (PIX), considerado a maior e mais importante reserva nacional no contexto cultural e de florestas no estado do Pará (DAVIDSON et al., 2012). Situada na porção Sul do Sudeste da Amazônia paraense, está conectada aos municípios de São Felix do Xingu e Santana do Araguaia (PA) e que, historicamente, fazem parte do arco do desmatamento da Amazônia Legal. A área cultural é formada por povos de diversas etnias, como os Awet, Kalapalo e Nahukuá. A despeito de sua variedade linguística, esses povos se caracterizam por uma grande similaridade no seu modo de vida e visão de mundo.

Nesse cenário, os municípios que estabeleceram os menores números de focos de calor estão aglomerados ao Nordeste da mesorregião. Desta forma, são classificados com densidades baixa e média, com manchas distribuídas uniformemente, porém, com um maior ajuntamento nos centros urbanos dos municípios, convergindo com o início do processo de urbanização política e demográfica.

Outro ponto associável a manchas de densidão é que esses municípios também exibem fatores em comum, por exemplo, possuem população total residente abaixo de 10 mil habitantes, exceto os municípios de São Domingos do Araguaia e Jacundá (PA), que, segundo o IBGE (2010), contam com uma população entre 20 e 50 mil habitantes e não possuem em suas dimensões geográficas áreas de reservas florestais devidamente demarcadas pelos órgãos ambientais como o IBAMA e a própria SEMA.

Para Fernandes et al. (2018), o processo de ocupação da maioria dos municípios dessa mesorregião iniciou em meados dos anos 1970, afluindo com o início das atividades operacionais da antiga Companhia Vale do Rio Doce (CVRD). Dez anos depois, já eram perceptíveis os aglomerados de casas, que deram início às primeiras vilas e distritos circunvizinhos ao empreendimento mineral.

Atualmente, há cidades emancipadas correspondendo demograficamente às áreas ocupadas anexas à passagem da rodovia PA 279 e 275, pois acompanham os condicionantes econômicos do ciclo de exploração mineral, sendo que a relativa desmobilização do formato company town pela CVRD decorreu tanto dos interesses de acumulação de capital da empresa quanto pela pressão migratória estimulada pela Estrada de Ferro Carajás, tornando-se fator impeditivo à manutenção do formato isolado núcleo urbano organizado versus núcleo urbano desestruturado (TRINDADE et al., 2015).

Os novos eixos de integração nacional permitiram maior articulação e crescimento de cidades médias no interior do Pará, tendência intensificada na medida em que o transporte ferroviário para escoamento da produção de minérios e madeira foi sendo incorporado, ligando ao Porto do Itaqui, São Luiz (MA).

Belchior; Primo (2016), em um estudo contemporâneo sobre as responsabilidades civis em desastres ambientais, a priori em uma retrospectiva do caso Mariana (MG) e Samarco Minerações S/A, que gerou o maior acidente ambiental, de repercussão internacional, dos últimos tempos no Brasil, apontaram que o desenvolvimento humano e econômico das sociedades hodiernas está condicionado diretamente pela produção de riquezas, muitas destas encontradas no meio natural, do qual todos os biomas existentes dependem e do qual precisam para se perpetuarem sobre a terra. $\mathrm{O}$ contato direto com essas áreas, sem nenhum planejamento ou ordenamento, comprometerá sua existência.

Becker (2015), estudando o Zoneamento EcológicoEconômico (ZEE) na Amazônia Legal, identificou que o município de Marabá (PA), situado ao Nordeste da 
mesorregião de estudo, apontou altas taxas de desmatamento entre os períodos de 2000 a 2015. Os resultados demonstram que houve crescimento das áreas desmatadas a uma taxa aproximada de $1 \%$ ao ano. A distribuição espacial dos dados demonstrou também que o desmatamento acontece de maneira distribuída no município, com superioridade sentido Sul para Norte.

Em geral, Oliveira; Piffer (2017) enfatizam que toda a ocupação territorial dessa área costuma chamar a atenção para alguns aspectos que dizem respeito principalmente: ao processo de industrialização, aos problemas agrários, às diversidades regionais e à migração campo-cidade como elementos-chave capazes de explicar o processo caótico de metropolização no país.

Santana et al. (2018) resumem que a proporção exacerbadora de focos de calor é iniciada por atividades humanas, mesmo que muitas dessas ocorrências não tenham sido de modo intencional, mas, sim, como resultado de ações motivadas pela desigualdade social, desvalorização dos recursos naturais, cultura e educação ambiental, falta de políticas e de manejo dos recursos florestais pelas comunidades.

Desta forma, notou-se evolução sistêmica com a prática do uso do fogo, resultante do preparo de terras para agricultura e pecuária, especialmente no período de queima, que começa com a estação seca e se estende de junho a outubro, dependendo do regime particular de precipitação do ano.

O estudo realizado por Artaxo et al. (2014), financiado pelos recursos do programa LBA (Programa de Grande Escala da Biosfera-Atmosfera na Amazônia), resultou na afirmação sobre as ligações entre o clima e o uso da terra na Amazônia e o funcionamento do bioma. No estudo, os autores afiançam que a vegetação tem uma estreita relação com a atmosfera, controlando uma série de processos físico-químicos que influenciam a taxa de formação de nuvens, quantidade de núcleos de condensação de nuvens, quantidade de vapor de água, emissão de gases biogênicos e de efeito estufa, entre tantas outras propriedades.

A Amazônia também é parte do mais intenso ciclo hidrológico de nosso planeta, com um contrafeito processamento e reciclagem de vapor de água que alimenta a maior bacia hidrológica. Estas feições fazem da região amazônica um pleito central em pesquisas de clima e nas mudanças globais.

Assim, torna-se importante fomentar que, em função da fragilidade dos dados, o Governo Federal precisa aprimorar suas informações oficiais sobre focos de calor, expandido seu monitoramento geoespacial para áreas mais estratégicas, como Nordeste, Sudeste e Sul da Amazônia paraense, possibilitando acurácia da realidade ambiental ou até mesmo para elaborar suas próprias políticas de prevenção e combate. A priori, sobre tais municípios, existe uma elevada carência de políticas públicas eficazes, configurando uma incerteza sobre a proteção dos recursos naturais em virtude dos atuais desmontes governamentais em áreas de combate às mudanças climáticas e desmatamento, que afetam diretamente a soberania da Amazônia brasileira.

Contudo, o estudo é um importante esforço para delinear o perfil dos focos de calor na mesorregião estudada dados os incipientes eventos, principalmente a urbanização e o crescimento populacional.

\section{CONCLUSÕES}

O ano de 2010 teve os maiores registros de focos de calor e de áreas queimadas e desmatadas. Os municípios de São Felix do Xingu e Cumaru do Norte, situados ao Sul da mesorregião, registrou a maior média e taxa anual de ocorrências de focos calor, provavelmente por fazerem parte do arco do desmatamento da Amazônia, que atualmente assola a região. Há indícios também de atividades como pecuária e aumento da extração de madeiras após a instalação de indústrias de produção de carvão vegetal, sintonizando um alerta geral à comunidade científica sobre o aumento do desmatamento, principalmente em áreas ambientalmente protegidas.

No geral, os anos com ocorrência do fenômeno El Niño foram associados a maiores índices de ocorrências de focos de calor na mesorregião estudada. Todavia, é de se relevar também a atuação de planos e programas de proteção ambiental, sobretudo que deram origem a sistemas operacionais mais aprimorados de monitoramento das florestas como o PRODES e o DETER. Fica irrefutável que na Amazônia paraense, a grande ocorrência de focos de calor está associada à atividade humana, como resultado do enfrentamento de questões sociais, culturais e políticas.

As estatísticas descritivas de ocorrência de focos de calor podem contribuir para dar embasamento às políticas públicas, pelo conhecimento em série histórica, de maior registro de focos e mudanças ocorridas ao longo da janela temporal. Por fim, almeja colaborar com evidências científicas, justificando a necessidade de expansão do monitoramento controlado e compartilhado, com informações em tempo real, visando gerir processos fiscalizatórios, primordialmente em municípios que fazem linha de frente à nova fronteira agrícola no Brasil.

\section{AGRADECIMENTOS}

Agradecemos à Coordenação de Aperfeiçoamento de Pessoal de Nível Superior (CAPES), pelo apoio financeiro via Bolsa de Pesquisa - Novo Programa de Formação Doutoral Docente - Portaria $n^{\circ} 140$, de 02 de outubro de 2013. À UFRA, pelo apoio de infraestrutura, à UNEMAT, pela disponibilidade no acesso interno do período da CAPES e ao INPE, pela utilização dos dados do Portal Bdqueimadas e do Programa (PRODES)

\section{REFERÊNCIAS}

ARTAXO, P.; DIAS, M. A. F. D. S.; NAGY, L.; LUIZÃO, F. J.; CUNHA, H. B. D.; QUESADA, C. A. Perspectivas de pesquisas na relação entre clima e o funcionamento da floresta Amazônica. Ciência e Cultura, São Paulo-SP, v. 66, n. 3, p. 41-46, 2014. DOI: http://dx.doi.org/10.21800/S0009-67252014000300014

ASSIS, F. R. V.; MENDONÇA, I. F. C.; SILVA, J. E. R. Uso de geotecnologias na locação espacial de torres para detecção de incêndios florestais no semiárido nordestino. Floresta, Curitiba-PR, v. 44, n. 1, p. 133 - 142, 2014. DOI: http://dx.doi.org/10.5380/rf.v44i1.32618

BASTOS, T. X. O clima da Amazônia Brasileira segundo Köppen. Belém, PA. EMBRAPA-CPATU, 1982. 4 p.

BECKER, B. K. Amazônia: mudança climática, projetos globais e interesse nacional. Parcerias Estratégicas, Brasília-DF, v. 18, n. 36, p. 107-128, 2015.

BELCHIOR, G. P. N.; PRIMO, D. A. S. A responsabilidade civil por dano ambiental e o caso Samarco: desafios à luz do paradigma da sociedade de risco e da complexidade 
ambiental. Revista Jurídica da FA7, Brasília-DF, v. 13, n. $1, \quad$ p. $10-30, \quad 2016$ DOI: http://dx.doi.org/10.24067/rju7,13.1:38

COSTA, A. M. S.; BEZERRA, P. E. S.; OLIVEIRA, R. S. de. Mudanças no uso e ocupação da terra associadas a focos de calor na área de influência da Rodovia BR-163 (CuiabáSantarém). Revista Brasileira de Gestão Ambiental, Pombal-PB, v. 11, n. 1, p. 119-125, 2017.

DAVIDSON, E. A.; ARAÚJO, A. C. de; ARTAXO, P.; BALCH, J. K.; BROWN, I. F. The Amazon basin in transition. Nature, v. 481, n. 7381, p. 321-328, 2012. DOI: https://dx.doi.org/10.1038/nature10717

FERNANDES, T.; HACON, S. S.; NOVAIS, J. W. Z., SOUZA, I. P.; FERNANDES, T. Detecção e análise de focos de calor no município de Parauapebas-PA, Brasil por meio da aplicação de geotecnologia. Enciclopédia Biosfera, Goiânia-GO, v. 15, n. 28, p. 398, 2018. DOI: http://dx.doi.org/10.18677/EnciBio 2018B34

FONSECA, A.; JUSTINO, M.; CARDOSO, D.; RIBEIRO, J.; SALOMÃO, R. Boletim do desmatamento da Amazônia Legal (fevereiro de 2019). Belém-PA: IMAZON, 2019. 1 p.

HERAWATI, H.; SANTOSO, H. Susceptibilidade e risco de incêndio de florestas tropicais sob mudanças climáticas: Uma revisão da natureza, política e instituições de incêndio na Indonésia. Política Florestal e Economia, v. 13, n. 4, p. 227-233, 2011.

HOFFMANN, E. L.; DALLACORT, R.; CARVALHO, M. A. C.; YAMASHITA, O. M.; BARBIERI, J. D. Variabilidade das Chuvas no Sudeste da Amazônia paraense, Brasil. Revista Brasileira de Geografia Física, São José dos Campos-SP, v. 11, n. 04, 1251-1263, 2018. DOI: https://dx.doi.org/10.26848/rbgf.v11.4.p1251-1263

IBGE INSTITUTO BRASILEIRO DE GEOGRAFIA E ESTATÍSTICA. Dados dos municípios do Estado do Pará, Brasil. 2010. Disponível em: $<$ https://cidades.ibge.gov.br/>. Acesso em: 29 dez. 2018.

INMET_INSTITUTO NACIONAL DE METEOROLOGIA. Banco de dados meteorológicos. 2017. Disponível em: $<$ http://www.inmet.gov.br/portal/>. Acesso em: 02 jan. 2019.

INPE INSTITUTO NACIONAL DE PESQUISAS ESPACIAIS. Dados pontuais de focos ativos de calor Sistema de Deteç̧ão de Desmatamento em Tempo Real - DETER. $2017 . \quad$ Disponível em: $<$ http://www.inpe.br/queimadas/portal/estatistica_estado $>$ . Acesso em: 28 dez. 2018.

INPE_INSTITUTO NACIONAL DE PESQUISAS ESPACIAIS. Banco de dados de queimadas - Programa Bdqueimadas para o território brasileiro. 2018. Disponível em: $<$ http://www.inpe.br/queimadas/bdqueimadas/>. Acesso em: 30 dez. 2018.

ISHIHARA, J.; FERNANDES, L.; DUARTE, A. Avaliação do monitoramento pluviométrico da Amazônia Legal. Revista Engenharia Ambiental: Pesquisa e Tecnologia, Espírito Santo do Pinhal-SP, v. 10, n. 3, 2013.

LOURENÇO, L. Incêndios florestais em Portugal continental fora do "período crítico", estudados numa tese que fornece importantes contributos para o seu conhecimento. Territorium, Coimbra, n. 25, n. 1, p. 151154, 2018. DOI: http://dx.doi.org/10.14195/1647$7723 \_25-1 \_13$
LOPES, A. C. L.; FREITAS, A. V. M.; COSTA, D. O. da; BELTRÃO, N. E. S.; TAVARES, P. A. Análise da distribuição de focos de calor no município de Novo Progresso, Pará. Revista Verde de Agroecologia e Desenvolvimento Sustentável, Pombal-PB, v. 12, n. 2, p. 298-303, 2017.

DOI: http://dx.doi.org/10.18378/rvads.v12i2.4843

MARTINS, F. C. O. Caracterização limnológica e aplicação do modelo DPSIR visando à avaliação integrada de bacias hidrográficas lacustres. Ambiência, Guarapuava-PR, v. 12, n. 2, p. 573-597, 2016. DOI: http://dx.doi.org/10.5935/ambiencia.2016.02.05

MELLO, N. G. R.; ARTAXO, P. Evolução do plano de ação para prevenção e controle do desmatamento na Amazônia legal. Revista do Instituto de Estudos Brasileiros, São Paulo-SP, v. 5, n. 66, p. 108-129, 2017. DOI: http://dx.doi.org/10.11606/issn.2316-901x.v0i66p108129

NOVAIS, J. W. Z.; SANTANNA, F. B.; ARRUDA, P. H. Z.; PEREIRA, O. A. Relação entre profundidade óptica de aerossóis e radiação fotossinteticamente ativa e global no cerrado Mato-grossense. Revista Estudo \& Debate, Lajeado-RS, v. 24, n. 1, p. 153-167, 2017. DOI: http://dx.doi.org/10.22410/issn.1983036X.v24ila2017.11 80

OLIVEIRA, T. J. A.; PIFFER, M. Do Sudeste da Amazônia Legal ao Centro Norte: as transformações econômicas espaciais. Revista Brasileira de Estudos Urbanos e Regionais (RBEUR), São Paulo-SP, v. 19, n. 1, p. 164178, 2017. DOI: http://dx.doi.org/10.22296/23171529.2017v19n1p164

PRODES - Programa de Monitoramento da Floresta Amazônica Brasileira por Satélite. Dados sobre desmatamento e queimadas no Brasil. Disponível em: $<$ http://www.obt.inpe.br/OBT/assuntos/programas/am azonia/prodes $>$. Acesso em: 06 de jan. 2018.

SANTANA, A. C.; SANTANA, Á. L. de; OLIVEIRA, G. M. T. S.; SANTANA, Á. L.; QUARESMA, J. L. A importância dos serviços ecossistêmicos para o desenvolvimento econômico e o bem-estar social na percepção da população: o caso da Floresta Nacional de Carajás. Nativa, Sinop-MT, v. 6, n. especial, p. 689-698, dez. 2018.

DOI: http://dx.doi.org/10.31413/nativa.v6i0.6418

SILVA, E. C. G.; FIEDLER, N. C.; JUVANHOL, R. S.; SILVA, G. M. A.; NEVES, F. P. Análise temporal da ocorrência de incêndios florestais nas Américas e região do Caribe. Nativa, Sinop-MT, v. 6, n. 5, p. 491-496, 2018. DOI: http://dx.doi.org/10.31413/nativa.v6i5.5845

SOARES, A. S. D.; PAZ, A. R. da P.; PICCILLI, D. G. A. Avaliação das estimativas de chuva do satélite TRMM no Estado da Paraíba. Revista Brasileira de Recursos Hídricos, Porto Alegre-RS, v. 21, n. 2, p. 288-299, 2016. DOI: http://dx.doi.org/10.21168/rbrh.v21n2.p288-299

TORRES, F. T. P.; ROQUE, M. P. B.; LIMA, G. S.; MARTINS, S. V.; DE FARIA, A. L. L. Mapeamento do Risco de Incêndios Florestais Utilizando Técnicas de Geoprocessamento. Floresta e Ambiente, Rio de JaneiroRJ, v. 24, 2017. DOI: http://dx.doi.org/10.1590/21798087.025615

THOMAZ, E. L.; ANTONELI, V.; DOERR, S. H. Effects of fire on the physicochemical properties of soil in a slashandburn agriculture. Catena, Amsterdam, v. 122, p. 209- 
215 ,

2014.

DOI:

https://dx.doi.org/10.1016/j.catena.2014.06.016

TRINDADE, J. R. B.; OLIVEIRA, W. P. de; NASCIMENTO

BORGES, G. T. do. O ciclo mineral e a urgência de políticas de desenvolvimento local: o caso do município de Parauapebas no sudeste do Estado do Pará. Revista de Políticas Públicas, Maranhão-MA, v. 18, n. 2, p. 603-618, 2015. DOI: http://dx.doi.org/10.18764/21782865.v18n2p603-618

XIA, C.; LI, Y. Evaluation of Ecological Construction in Kunming using the DPSIR Model. International Journal of Technology, New York, v. 9, n. 7, p. 1338-1345, 2018. DOI: https://dx.doi.org/10.14716/ijtech.v9i7.2489 